\title{
Trends in the Aggregate Labor Force
}

\author{
Kenneth J. Matheny
}

\begin{abstract}
Trend growth in the labor force is a key determinant of trends in employment and gross domestic product (GDP). Forecasts by Macroeconomic Advisers (MA) have long anticipated a marked slowing in trend growth of the labor force that would contribute to a slowing in potential GDP growth. This is reflected in MA's forecast that the aggregate rate of labor force participation will trend down, especially after 2010, largely in response to the aging of the baby boom generation, whose members are beginning to approach typical retirement ages. Expectations for a downward trajectory for the participation rate and a slowing in trend labor force growth are not unique. However, this article reports on MA research suggesting that the opposite is possible: that the slowdown in trend labor force growth could be relatively modest and that the trend in the aggregate rate of labor force participation will decline little, if at all, over the next decade. (JEL E01, J11)
\end{abstract}

Federal Reserve Bank of St. Louis Review, July/August 2009, 91(4), pp. 297-309.

$\mathbf{P}$

rojections of population and labor force growth are essential elements of any projection of the economy's potential output growth. Often, however, these projections are driven primarily by trends and dummy variables. The research reported here constructs a labor force projection from a much richer set of behavioral determinants of labor force trends than are typically used. The set of determinants also is richer than that contained in the aggregate labor force equation that appears in the current version (as of this writing) of the Macroeconomic Advisers (MA) commercial macroeconomic model.

In its September 24, 2008, issue of Long-Term Economic Outlook, MA projected that the labor force participation rate would decline by about
$1 \frac{1 / 2}{2}$ percentage points over the next decade-to 64.6 percent in 2017-and that the growth of the labor force would slow from roughly 1 percent or a little higher on average in recent years to an average of 0.6 percent from 2013 to 2017 (Tables 1 and 2). These estimates are comparable to recent estimates from the Congressional Budget Office. However, they are considerably stronger than trend estimates in a recent paper by Aaronson et al. (2006). Their research suggests that demographic and other developments could result in a much larger decline in the participation rate-to 62.5 percent by the middle of the next decade-and a reduction in trend labor force growth to just 0.2 percent from 2013 to 2015.

The research summarized here leans in the other direction. It suggests that trend growth of

Kenneth J. Matheny is a senior economist at Macroeconomic Advisers, LLC. The author thanks James Morley of Washington University for research advice and assistance. Other staff at Macroeconomic Advisers contributed to this research in various ways, including Joel Prakken, chairman; Chris Varvares, president; Ben Herzon, senior economist; Neal Ghosh, economic analyst; and Kristin Krapja, economic analyst. The author also acknowledges the following for their assistance or feedback: Robert Arnold, Congressional Budget Office; Jonathan Pingle, Brevan Howard Asset Management, LLP; Mary Bowler, Sharon Cohany, John Glaser, Emy Sok, Shawn Sprague, and especially Steve Hipple and Mitra Toosi of the Bureau of Labor Statistics; Steven Braun of the President's Council of Economic Advisers; and William Wascher of the Federal Reserve Board of Governors. The staff of Haver Analytics provided assistance locating certain data. Ross Andrese, a former employee of Macroeconomic Advisers, provided research assistance during an early phase of this project.

(C) 2009, The Federal Reserve Bank of St. Louis. The views expressed in this article are those of the author(s) and do not necessarily reflect the views of the Federal Reserve System, the Board of Governors, or the regional Federal Reserve Banks. Articles may be reprinted, reproduced, published, distributed, displayed, and transmitted in their entirety if copyright notice, author name(s), and full citation are included. Abstracts, synopses, and other derivative works may be made only with prior written permission of the Federal Reserve Bank of St. Louis. 
Table 1

Growth of the Civilian Labor Force

\begin{tabular}{ccccc} 
Year & $\begin{array}{c}\text { MA Long-Term } \\
\text { Economic Outlook (2008) }\end{array}$ & $\begin{array}{c}\text { Model } \\
\text { prediction of trend* }\end{array}$ & $\begin{array}{c}\text { CBO (2008) } \\
\text { estimate of trend }\end{array}$ & $\begin{array}{c}\text { Aaronson et al. (2006) } \\
\text { estimate of trend }\end{array}$ \\
\hline 2008 & 0.8 & 1.3 & 1.1 & 0.4 \\
2009 & 0.8 & 1.1 & 1.0 & 0.4 \\
2010 & 1.1 & 0.9 & 0.9 & 0.4 \\
2011 & 1.0 & 0.9 & 0.6 & 0.4 \\
2012 & 0.8 & 0.9 & 0.6 & 0.3 \\
2013 & 0.6 & 1.0 & 0.6 & 0.2 \\
2014 & 0.6 & 0.9 & 0.5 & 0.2 \\
2015 & 0.6 & 0.9 & 0.5 & 0.2 \\
2016 & 0.6 & 0.9 & & NA \\
2017 & 0.6 & 0.9 & 0.5 & NA
\end{tabular}

NOTE: Data represent annual averages in percent. *Based on the level terms of the regression in Table 3 after removing cyclical contributions from the unemployment and wealth terms, as described in the text.

\section{Table 2}

\section{Labor Force Participation Rate}

\begin{tabular}{ccccc} 
Year & $\begin{array}{c}\text { MA Long-Term } \\
\text { Economic Outlook (2008) }\end{array}$ & $\begin{array}{c}\text { Model } \\
\text { prediction of trend* }\end{array}$ & $\begin{array}{c}\text { CBO (2008) } \\
\text { estimate of trend }\end{array}$ & $\begin{array}{c}\text { Aaronson et al. (2006) } \\
\text { estimate of trend }\end{array}$ \\
\hline 2008 & 66.0 & 65.7 & 66.1 & 65.2 \\
2009 & 65.9 & 65.8 & 66.0 & 64.7 \\
2010 & 65.8 & 65.7 & 65.9 & 64.4 \\
2011 & 65.8 & 65.7 & 65.7 & 64.0 \\
2012 & 65.7 & 65.7 & 65.4 & 63.7 \\
2013 & 65.5 & 56.8 & 65.2 & 63.3 \\
2014 & 65.3 & 65.9 & 64.9 & 62.9 \\
2015 & 65.1 & 66.0 & 64.6 & 62.5 \\
2016 & 64.9 & 66.0 & 64.3 & NA \\
2017 & 64.6 & 66.0 & 63.9 & NA
\end{tabular}

NOTE: Data represent annual averages in percent. *Based on the level terms of the regression in Table 3 after removing cyclical contributions from the unemployment and wealth terms, as described in the text. 
the labor force might not slow as much over the next decade as previously anticipated. According to the model, the trend in labor force growth will edge down slightly to an average of 0.9 percent through 2017, and the trend in the labor force participation rate will dip only slightly from recent levels to average just under 66 percent from now through 2017. The research reported here updates our measure of the pure demographic contribution to the change in the labor force to reflect more age detail than in our existing model and to match the population concept on which it is based with the one that underpins the official estimates of the labor force and the participation rate from the Bureau of Labor Statistics (BLS). The updated model addresses a bedeviling problem with discontinuities in the official estimates of the labor force and the civilian noninstitutional population. Unfortunately, data limitations prevent the complete elimination of the spurious impacts of these discontinuities, which stem from updates to "population controls" that are entered into the official data in response to the results of decennial censuses and for other population-related data.

The research reported here shows a much richer set of behavioral determinants of labor force trends than are contained in the equation for the aggregate labor force that appears in the MA commercial model at the time of this writing. Specifically, this analysis drops previously used deterministic trend and shift terms; instead, the model includes a small set of factors believed to exert important behavioral influences on the labor force.

\section{DEMOGRAPHIC CONTRIBUTION TO THE LABOR FORCE}

As part of our modeling, the pure demographic contribution to the change in the labor force is separated from its behavioral influences. We typically measure the demographic contribution with a chain-weighted index of the populations for 30 different age and gender brackets, using lagged labor force participation rates as weights, which we label $L F C A D J L .{ }^{1}$ Population details from the civilian noninstitutional population 16 years and older are used to construct the series. With lower-case $p$ 's denoting participation rates and lower-case nc's denoting population details, $L F C A D J L$ is updated according to

$$
\begin{aligned}
& \operatorname{LFCADJL}_{t}=L F C A D J L_{t-1} \times \\
& \left(\sum_{i=1}^{30} p_{i, t-1} \times n C_{i, t}\right) /\left(\sum_{i=1}^{30} p_{i, t-1} \times n C_{i, t-1}\right) .
\end{aligned}
$$

The series is indexed to equal the actual labor force in 2000. (This has no impact on the results that follow.) Changes in $L F C A D J L$ from one quarter to the next are due to changes in the detailed populations across age and gender brackets (the $n c$ 's) holding fixed the weights (the $p$ 's). In this sense, growth of $L F C A D J L$ is a comprehensive measure of the pure demographic contribution to the change in the labor force. Growth of the actual labor force and growth of LFCADJL are displayed together in Figure $1 .^{2}$ Forecast projections for $L F C A D J L$ reflect growth in the population detail, holding fixed the within-group participation rates. We observe that growth of LFCADJL is projected to moderate in the forecast, with an average of 0.4 percent from 2015 to 2017.

\section{BEHAVIORAL COMPONENT OF THE LABOR FORCE}

The behavioral component of the labor force can be measured by the log-ratio of the actual labor force to the demographic measure, $\log (L F C / L F C A D J L)$. This series (Figure 2 ) is obviously nonstationary, and tests confirm that it appears to be I(1), that is, the series is stationary after differencing, implying that cointegrationbased techniques provide a useful framework for econometric analysis. We found evidence that this

\footnotetext{
1 Male and female populations and labor forces are separated into 15 non-overlapping age brackets, specifically, 16-17, 18-19, 20-24, 25-29, 30-34, 35-39, 40-44, 45-49, 50-54, 55-59, 60-61, 62-64, 65-69, 70-74, and 75 years and older.

2 We return in a subsequent section to the appearance of sharp swings in the growth rates of these series stemming from updated population controls that are entered into the population and labor force data without adjustment. The most recent discontinuity occurs in data for the first quarter of 2008, reflected in a sharp, temporary drop in the growth of LFCADJL.
} 
Figure 1

Labor Force Growth: Actual and Demographic Contribution

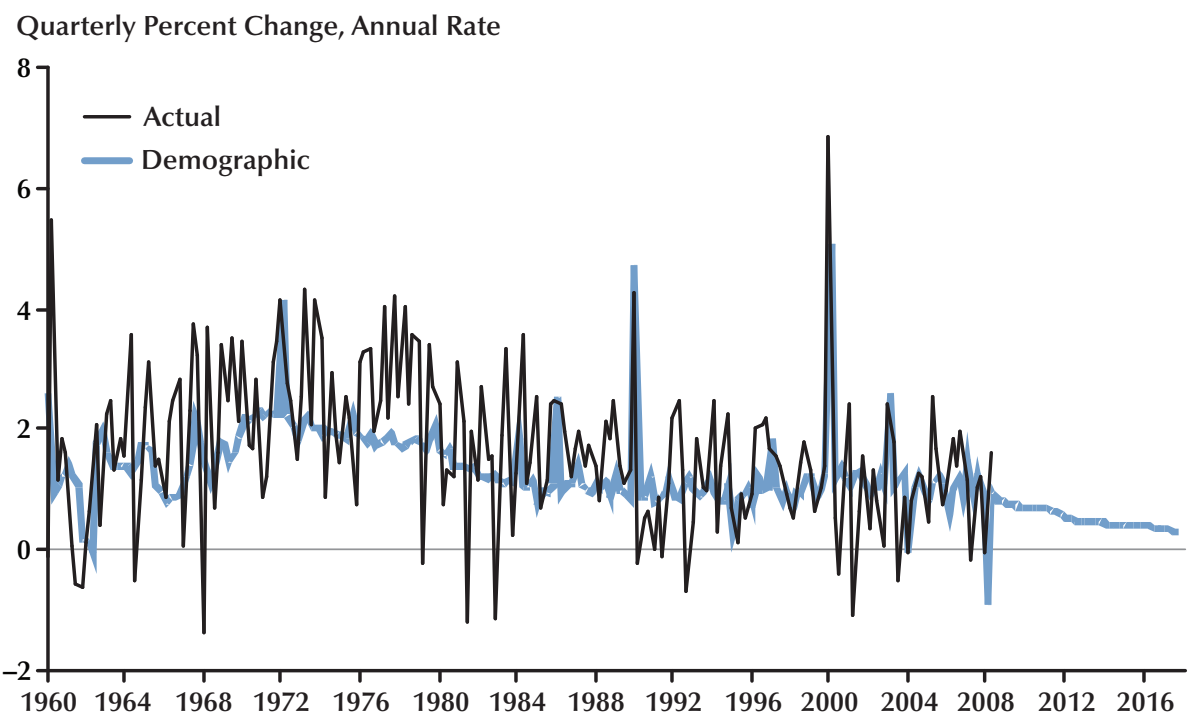

SOURCE: BLS and MA.

\section{Figure 2}

\section{Prediction for Behavioral Component}

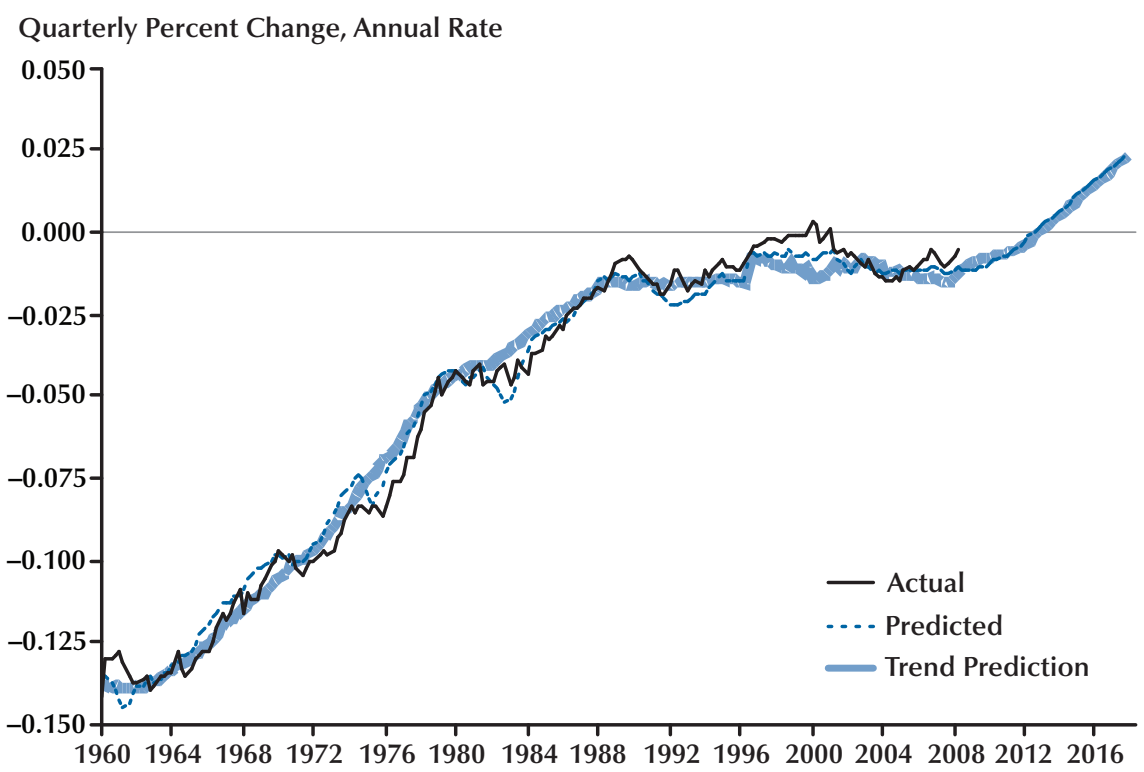


variable is cointegrated with the following set of "behavioral" variables (and a constant).

Dependency Ratio (YOUNG015): The ratio of persons 15 years and younger to the entire resident population. This series has generally trended down over the past several decades, roughly mirroring the inverse of the relative participation rate for women. This term is typically among the most robust and statistically significant variables in labor force regressions.

Life Expectancy (WT65F_LEF65): The life expectancy of women at the age of 65 years, multiplied by the share of women aged 65 and older in the total adult, civilian, noninstitutional population. Life expectancy represents the number of years one would expect to live, on average, conditional on having attained the age of $65 .^{3}$ A subsequent section addresses our choice of a female-weighted, female life expectancy.

Welfare Reform (WR1996): Intended as a proxy for the effect of welfare reform in the late 1990s. This series is constructed as the product of several terms, beginning with a dummy variable that is zero up to the second quarter of 1996 and one thereafter, to mark the enactment of federal welfare reform in August 1996. ${ }^{4}$ The zero-one dummy is multiplied by one minus the share of women who are married, by the dependency ratio (YOUNG015), and by the ratio of the population of women aged 18 to 49 to the total adult civilian noninstitutional population. ${ }^{5}$

3 Estimates for life expectancy are from the "intermediate-cost" assumptions of the Social Security Administration (www.ssa.gov/ OACT/TR/TR07/lr5A4.html). Interpolation from annual to quarterly estimates is accomplished using a cubic spline. We take a centered nine-quarter moving average to smooth sometimes odd movements in the first differences that arise because of interpolation. Smoothing has very little effect on the regression results.

4 The Personal Responsibility and Work Opportunity Reconciliation Act of 1996 was signed into law by President Clinton on August 22, 1996. Some states began instituting welfare reforms during the same era or before. We also considered slightly different versions of this term where the dummy variable switches from zero to one either before or after the third quarter of 1996. For dates near the third quarter of 1996, the regression results were little affected.

${ }^{5}$ One might suppose that, in the regression, the welfare reform term is capturing a behavioral increase in the labor force as persons were "pulled" into labor markets during a period of strong labor demand beginning in the late 1990s. We discount this possibility for two reasons. First, the welfare reform term is significant with the unemployment rate present, and the unemployment rate arguably accounts for any "demand pull" effect. Second, the size of the effect from the welfare reform term is comparable to estimates from other researchers about the impact of welfare reform in the 1990s.
Household Net Worth (NW_SCALED5564): The ratio of per capita household net worth to hourly labor compensation, multiplied by the population share of persons aged 55 to 64 . The traditional theory of the labor/leisure choice notes that increases in wealth cause a reduction in labor supply if leisure is a "normal" good. However, previous research on the existence of wealth effects on labor supply has been mixed. ${ }^{6}$ We found ambiguous results when the wealth ratio is not scaled by the population share but robust results consistent with traditional theory when the wealth ratio is premultiplied by the share of the population aged 55 to 64 . In other research on participation rates for individual age brackets, we found evidence of wealth effects on participation rates for this age bracket.

Unemployment Rate (LURC): The official unemployment rate, expressed in percent. Its presence is motivated by search-theoretic considerations, namely, that the expected return to searching for employment is negatively related to the level of unemployment.

A simple levels regression among these variables and a constant suggested cointegration, so a dynamic levels regression was estimated that also includes leads and lags of the first differences of all the regressors to control for serial correlation. ${ }^{7}$ The results of the dynamic regression are summarized in Table $38^{8,9}$ All five regressors enter as expected, with positive coefficients on the life expectancy and welfare reform terms, and negative coefficients on the dependency ratio, the

6 Goodstein (2008) finds that increases in wealth do lead to earlier withdrawal from the labor force in a panel dataset of older men. He argues that previous researchers who investigated the issue in panel datasets found small and statistically insignificant effects of wealth on retirement because they did not control for differences in "tastes," including risk aversion and preference for work, thereby producing a spurious positive correlation between wealth and labor force participation.

7 Along with a correction for heteroskedasticity, $t$-statistics from the dynamic levels regression are asymptotically valid.

8 To conserve space, the differenced terms, which are immaterial to what follows, are suppressed in the table.

9 Sample means of the first-differenced terms were removed before estimation. This has no effect on the estimated coefficients, except for the constant, and ensures that the predicted value of the level terms is consistent with the level of the dependent variable during the estimation sample. 
unemployment rate, and the wealth term. All terms are statistically significant.

We noted at the outset that the primary focus of this research was on the determinants of trends in the labor force. Toward that end, we removed the direct "cyclical" contribution by replacing the unemployment rate $(L U R C)$ with our estimate of the long-run natural rate of unemployment (NAIRU). ${ }^{10}$ The wealth term is also subject to cyclical influences, though the issue of identifying its cyclical contribution is ambiguous. On the one hand, it might not matter much in the forecast beyond 2010, because the contribution from the wealth term does not vary much after that date. Nevertheless, we did attempt to reduce the obvious cyclicality in the wealth term as follows. First, we regressed the unscaled wealth ratio (that is, per capita wealth divided by hourly compensation without scaling by the population share) on several leads and lags of the unemployment rate, along with a constant and trend. We then substituted the contribution from the unemployment rate with a contribution computed using the NAIRU and the same coefficients. The adjusted wealth rate was once again multiplied by the 55- to 64-year-old population share $\left(N W \_S C A L E D 5564 L R\right) .{ }^{11}$

With these adjustments, the model for "trend" in the behavioral component of the labor force is given by

\footnotetext{
${ }^{10}$ Our estimate of the NAIRU is not a constant because it includes a gradually evolving adjustment for changes in the age profile of the labor force. For example, younger adults on average experience higher unemployment rates, so an increase in their share of the labor force would, all else equal, be associated with an increase in the unemployment rate.

${ }^{11}$ An alternative procedure to reduce the influence of cyclical movements in the unemployment rate on the model's prediction for the labor force would be to replace the unemployment rate with the NAIRU and to replace the original wealth term with the "adjusted" version when estimating the regression. In this alternative, the NAIRU is not statistically significant, but the coefficient on the adjusted wealth term is little changed. Moreover, there is a substantial increase in the coefficient on the life expectancy term that leads to a much higher forecast for the participation rate-approximately 2 percentage points higher by 2017-which we would be uncomfortable showing as a base-case scenario. In any event, this exercise suggests that the forecast projections based on the original model (derived from the level terms in the regression in Table 3) are not overly optimistic.
}

\section{$0.1233+0.0784 \times W T 65 F_{-} L E F 65_{t}-0.9330$}

(2) $\times$ YOUNG015 $+0.2146 \times W R 1996 Q 3_{t}-0.2682$ $\times N W_{-} S C A L E D 5564 L R_{t}-0.0048 \times \mathrm{NAIRU}_{t}$.

The coefficients in this expression are identical to those on the corresponding level terms in Table 3. The predicted value for this model over both history and forecast is displayed in Figure 2, along with a prediction that does not remove cyclical contributions from the unemployment rate. Forecast assumptions for the wealth ratio and the NAIRU are from MA's most recent Longterm Outlook publication.

The model easily incorporates the secular increase in the log-ratio from the early 1960s to the 1990s. It also easily replicates the flattening that began in the late 1990s and, to some extent, the downturn in the first half of the current decade. As of 2008:Q2, the actual and predicted ratios differ by just 0.6 percent. According to the model, about three-fourths of the increase in the ratio of $L F C$ to $L F C A D J L$ is "explained" by the dependency term, with most of the remainder accounted for by life expectancy, with smaller and roughly offsetting contributions on net from the other terms. According to the model, welfare reform raised the level of the labor force by approximately 0.75 percent beginning in 1996:Q3, or by about 1.0 million persons. This figure is comparable to estimates by other researchers of the impact of welfare reform. ${ }^{12}$ To a first approximation, the impact on the labor force from the welfare reform term is nearly constant through the end of the estimation sample and in the forecast. ${ }^{13}$ The esti-

\footnotetext{
12 Blank (2004) notes that between 1995 and 2001, a period over which, on net, there was little change in the aggregate unemployment rate, employment of single mothers rose by approximately 820,000 , as welfare caseloads fell by roughly double that amount. The author argues that 820,000 likely understates the full effect on employment of welfare reform. The impact on the labor force was likely even larger than the impact on employment. Bartik (2000) estimated that welfare reform expanded the labor force of less-skilled women by over 1 million persons.

${ }^{13}$ The value of WR1996 rises from zero to about 0.035 in 1996:Q3. On balance, it drifts down through the end of the estimation sample, to about 0.031 as of $2008: \mathrm{Q} 2$. Based on the estimated model in Table 3 , the percentage contribution from this term declined from about 0.75 percent in late 1996 to about 0.66 percent in early 2008 In level terms, the estimated contribution to the labor force in early 2008 (of 1 million persons) is essentially identical to the contribution from this term as of 1996:Q3.
} 


\section{Table 3}

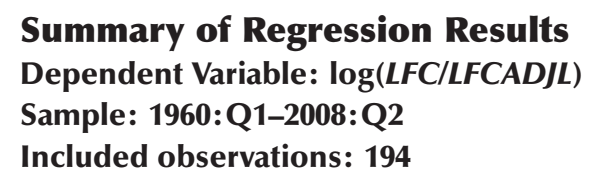

\begin{tabular}{lcccc} 
Variable & Coefficient & HAC SE & $\boldsymbol{t}$-Statistic & $\boldsymbol{p}$-Value \\
\hline CONSTANT & 0.0123 & 0.0392 & 3.1492 & 0.0020 \\
YOUNG015 & -0.9330 & 0.0556 & -16.7784 & 0.0000 \\
WTF65F_LEF65 & 0.0784 & 0.0135 & 5.7987 & 0.0000 \\
WR1996 & 0.2146 & 0.0761 & 2.8191 & 0.0055 \\
LURC & -0.0048 & 0.0005 & -10.7430 & 0.0000 \\
NW_SCALED5564 & -0.2682 & 0.0436 & -6.1487 & 0.0000
\end{tabular}

$\begin{array}{lclr}R^{2} & 0.9968 & \text { Mean dependent variable } & -0.0524 \\ \text { Adjusted } R^{2} & 0.9960 & \text { SD dependent variable } & 0.0473 \\ \text { Standard error of regression } & 0.0030 & \text { Akaike information criterion } & -8.5967 \\ \text { Sum squared residual } & 0.0014 & \text { Schwarz criterion } & -7.9061 \\ \text { Log likelihood } & 874.88 & \text { F-statistic } & 1,195.81 \\ \text { Durbin-Watson statistic } & 0.7750 & \text { Probability }(F \text {-statistic) } & 0.0000\end{array}$

NOTE: HAC SE, heteroskedasticity and autocorrelation consistent standard error; SD, standard deviation. Not shown are the coefficients on the leads and lags of first differences for each of the level regressors (excluding the constant). Three leads and lags and contemporaneous values were included for each of the differenced terms. Sample means were deducted from the first differences before estimation.

mate of "trend" for the behavioral component is a little higher than the unadjusted prediction for periods when the unemployment rate is above the NAIRU.

The model's forecast includes a pronounced upward movement in the behavioral component of the labor force, especially after 2011, mostly in response to an increasing (indeed, accelerating) contribution from the life expectancy term, along with a small increase in the contribution from the dependency term. The contribution from the welfare reform is nearly a constant in the forecast, and the contribution from the adjusted wealth term to the change in the forecast through 2017 is small. We return to a discussion of the life expectancy term and its contribution to the forecast in a subsequent section.

\section{DISCONTINUITIES IN POPULATION CONTROLS}

The historical time series on the civilian noninstitutional population periodically exhibits sharp swings stemming from changes in the population controls that are used to extrapolate survey results (population data are published by the U.S. Bureau of the Census in Current Population Survey). The reason is that when the population controls are updated, their effects are not normally backdated or smoothed when entered into the official estimates for the civilian noninstitutional population. For example, when the population control for January 2000 was raised to reflect the results of Census 2000, it led to an upward adjustment to the official estimate for the civilian noninstitutional population as of that date of 
approximately 2.6 million persons. Data for previous periods were not restated upward to reflect the new, higher population control for January 2000 , resulting in a discontinuity in the official data. ${ }^{14}$ Similar discontinuities surround previous decennial censuses and other dates. Discontinuities exist for the same reason in the official data on the labor force.

The existence of discontinuities affects our measure of the demographic contribution to the labor force, $L F C A D J L$, because the population details used in its construction are subject to the same discontinuities. This does not represent a problem for our regression analysis, because the estimates of the civilian labor force $(L F C)$ and $L F C A D J L$ are subject to discontinuities from the same source and are consistent. However, the existence of population control-related discontinuities does affect estimation of "trend" in these series (and in the civilian noninstitutional population). ${ }^{15}$

Estimates of the effect of revised population controls on the aggregates for the civilian noninstitutional population and for the total labor force are available in BLS publications for several decades of data, but detailed information necessary to smooth the impacts on the population details used to construct $L F C A D J L$ is not available. Given these discontinuities, what is the best way to proceed? Although highly imperfect, we adjust $L F C A D J L$ by multiplying it by the ratio of the adjusted to the unadjusted totals for the civilian noninstitutional population. This reduces but clearly does not eliminate some of the spikes in the growth of LFCADJL over history (Figure 3). As seen later, this results in extra variability in the model's prediction for trend growth of the labor force.

\footnotetext{
${ }^{14}$ The BLS estimates that the introduction of new population controls based on Census 2000 raised the civilian noninstitutional population 16 and older (N16C) and LFC by approximately 2.6 and 1.6 million, respectively. Civilian employment was raised by about 1.6 million at the same time. The aggregate unemployment rate was essentially unaffected by updated population controls based on Census 2000.

${ }^{15}$ The participation rates are usually not affected greatly by the introduction of updated population controls, as the revisions to the totals for the labor force and the civilian noninstitutional population are approximately proportional.
}

\section{AN ESTIMATE OF TREND GROWTH IN THE LABOR FORCE}

Figure 4 displays the growth rate of the civilian labor force after adjustments that smooth the effects of updated population controls, along with a forecast from MA's most recent long-term outlook. The figure also shows the prediction of the trend in the adjusted labor force. The latter includes the version of $L F C A D J L$ adjusted for revised population controls (the adjustment is admittedly incomplete) and the estimate of "trend" for the behavioral component of the labor force based on the model described previously. Figure 5 shows a corresponding set of estimates for the labor force participation rate.

One of the most obvious features is that the estimate of trend growth is not smooth, especially in history. In part this reflects changes in its behavioral determinants, but it also reflects discontinuities from updated population controls that, given available information, we are able to reduce but not eliminate. The spike in 1990 is an example, as are a pair of sharp declines in the 1960s.

According to the model, trend growth in the labor force peaked in the early 1970s at slightly below 3 percent; but it soon subsided and, for most of the 1980s and the first half of the 1990s, trend growth fluctuated between 1 and 2 percent. It rose briefly in 1996 in response to welfare reform. Declines in the net worth term generated brief increases in the model's prediction for potential labor force growth in the earlier 2000s and again recently (and through the first couple years of the forecast).

Turning to the forecast, trend growth of the labor force is projected to average 0.9 percent from 2008 to 2017, three-tenths of a percentage point higher than in our most recent forecast. The trend in the labor force participation rate is projected to edge down slightly but remain close to 66 percent throughout the forecast through 2017, well above our previous forecast of a decline to 64.6 percent by 2017 . The model's predictions are also higher than trend estimates from the Congressional Budget Office (2008) and especially those from Aaronson et al. (2006). 
Figure 3

Demographic Contribution to Labor Force Growth with Population Adjustments

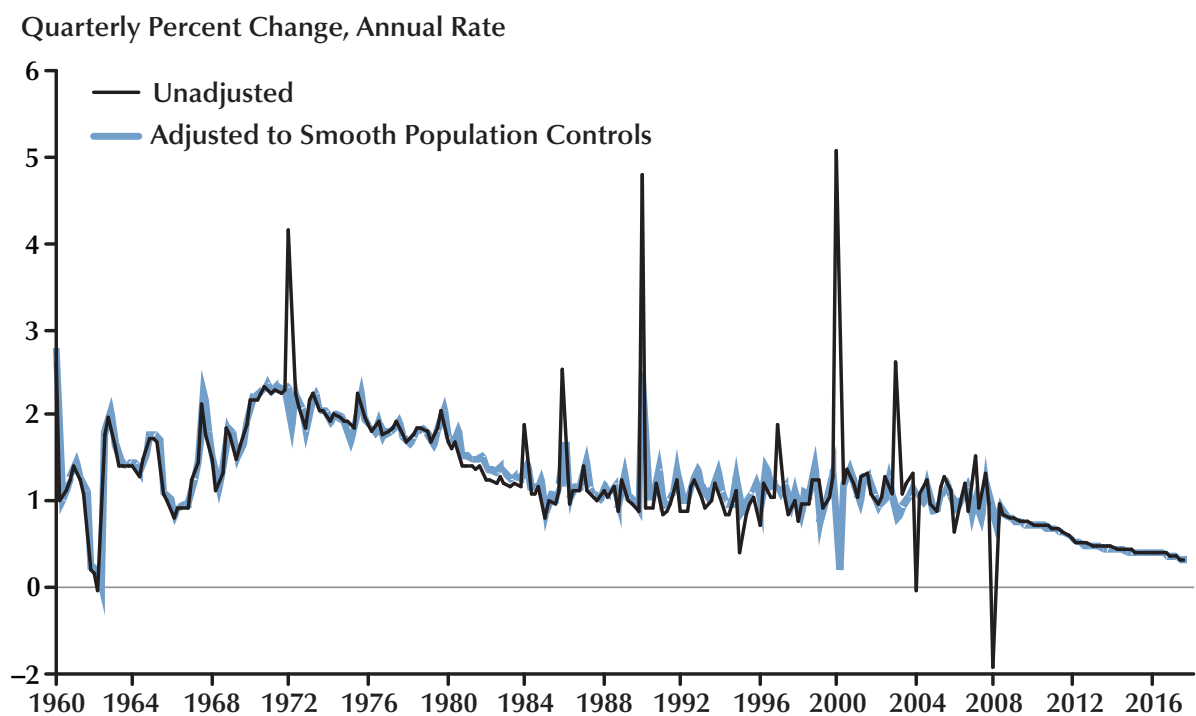

\section{Figure 4}

\section{Trend Growth of the Labor Force with Population Control Adjustments}

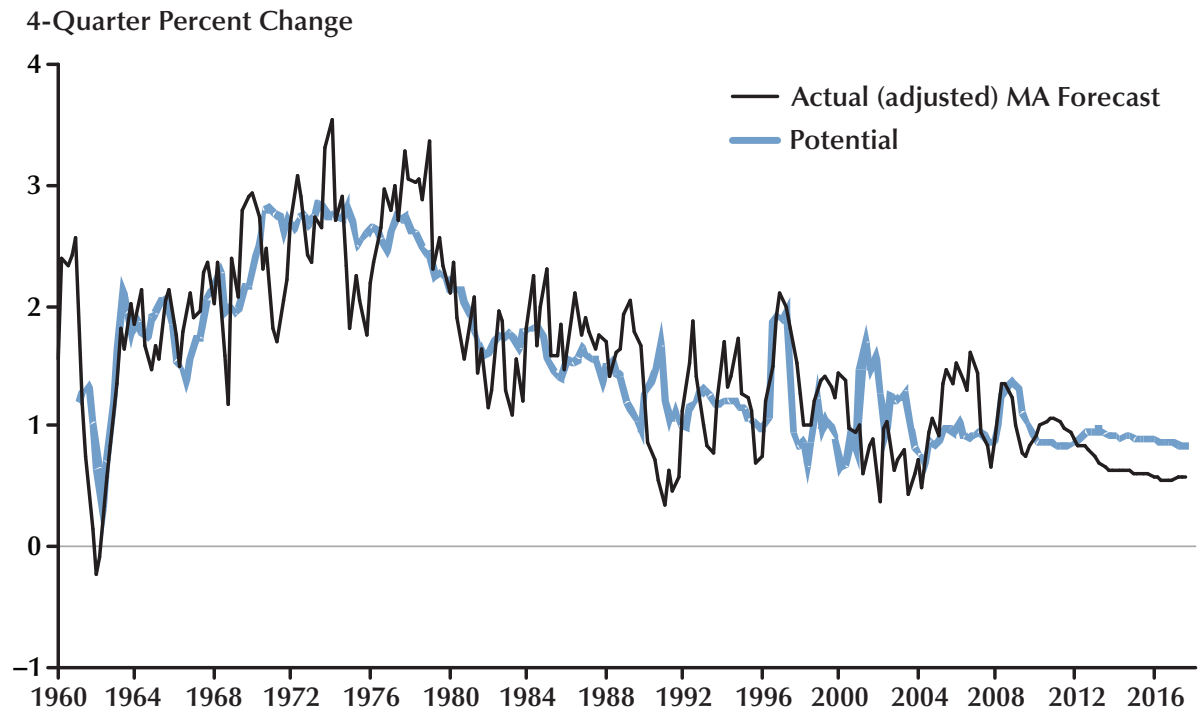


Figure 5

\section{Labor Force Participation (Actual and Trend) with Smoothed Population Controls}

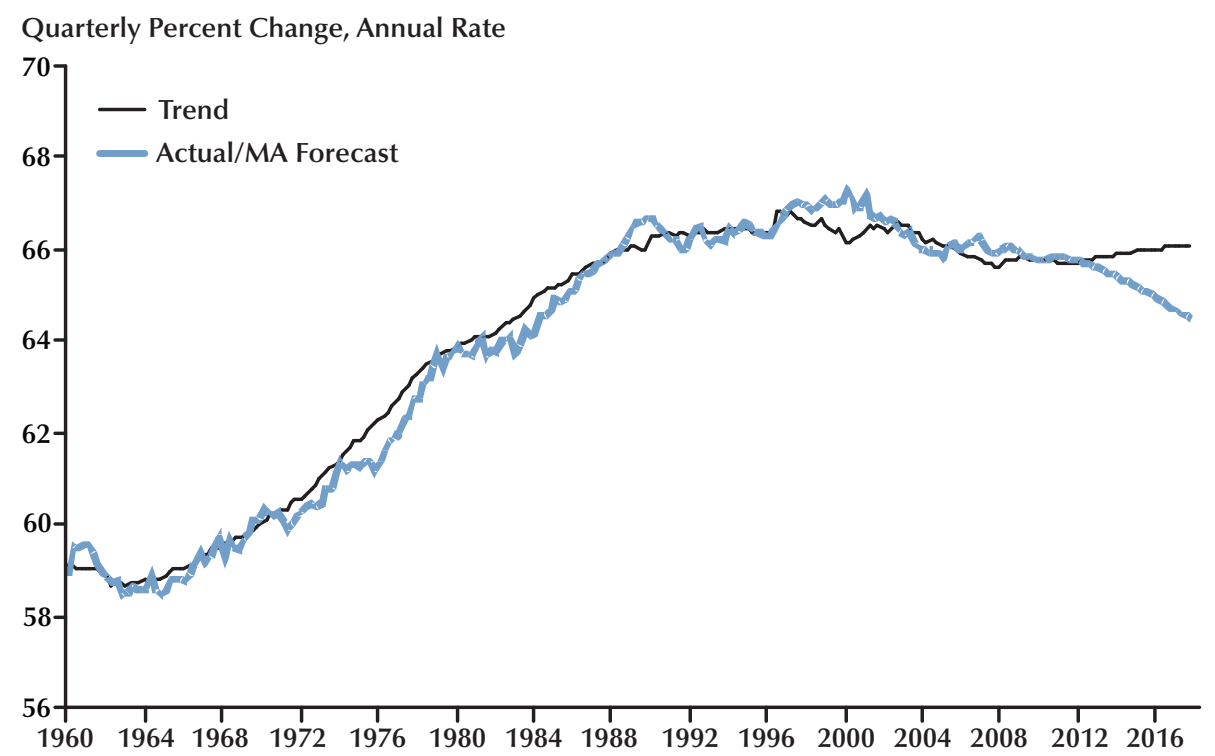

\section{MODEL SPECIFICATION DETAILS}

We contemplated a larger set of potential behavioral influences on the labor force than those shown in the model in Table 3. Many terms that were considered do not appear in the featured specification because the econometric results did not support their inclusion, including (i) the difference between the marginal and average net-oftax rates for labor income and the ratio of the marginal to the average net-of-tax rates; (ii) the marriage rate for women; (iii) the ratio of the female to the male participation rate; (iv) the ratio of after-tax Social Security retirement benefits to after-tax hourly labor compensation and the same ratio multiplied by the population share for age 65 and older; (v) a zero-one dummy variable for the elimination in 2000 of the Social Security earnings test for persons who have reached normal retirement age; (vi) replacement of the unemployment rate with separate regressors for the NAIRU and the difference between the unemployment rate and the NAIRU; and (vii) a linear time trend. ${ }^{16}$
Limitations on data availability and labor resources precluded assessing other factors that might influence work/retirement decisions, such as the cost of medical care; parameters that affect Social Security retirement benefits, such as a more nuanced assessment of changes in the earnings test, and changes to the delayed retirement credit; the evolution from defined-benefit to defined-contribution retirement plans; and edu-

${ }^{16}$ Although one of our goals was to develop a behavioral model without relying on ad hoc deterministic trends or shift terms, we did investigate the effect of adding a trend to evaluate whether one or more of the regressors in the featured specification appeared to be significant because it (or they) simply filled the role of a time trend. Fortunately, we did not find that to be the case. When a linear time trend is added to the regression for $\log (L F C / L F C A D J L)$, it enters with a negative coefficient and it is borderline statistically significant, with a $t$-statistic of -1.90 , while existing level regressors remained statistically significant. The coefficient on the life expectancy term rose by more than one-third and the sum of the contributions from the trend and life expectancy terms in the forecast would have resulted in a prediction for the participation rate that by 2017 is 0.5 percentage points higher than for the featured model. The prediction from the featured model is already stronger than existing forecasts, including our own previous long-term projection, so we are hesitant to adopt specifications that imply even faster labor force growth in the forecast without a compelling reason to do so, a hurdle that we did not feel was exceeded with a $t$-statistic of about -1.90 on a deterministic trend term. 
cational attainment and involvement. These issues certainly merit further investigation.

The labor force participation rate of young adults in the 16- to 19-year-old age bracket has declined from a peak near 59 percent in the late 1970s to 41 percent as of 2008:Q2. The possibility of further declines in the participation rate of this bracket might constitute a downside risk to projections for the labor force but one that we believe is small. If the participation rate of this age bracket fell during the forecast horizon at a pace comparable to its decline over the past decade (which is steeper than the decline over the entire period from the late 1970s to now), then it would, all else equal, lower the aggregate participation rate in 2017 by approximately 0.4 percentage points. Furthermore, we think the downside risk to the forecast could be even less than suggested by the static calculation. Why? First, our estimation sample, which begins in 1960, includes the entire period of decline in this age bracket, so the model should not be "surprised" by continued declines comparable to those experienced over history. Second, as noted previously, when we added a trend term to the model, the projection for the labor force was actually higher than for the featured model. Third, we tried adding a trend premultiplied by the population share for 16- to 19year-olds, but it was essentially zero, statistically insignificant ( $t$-statistic of -0.1), and produced no discernible changes in other coefficients or in the model's predictions. ${ }^{17}$ Splitting the weighted trend into separate terms for the period up to 1978 and thereafter was equally ineffective. Finally, the decline in the participation rate of 16- to 19year-olds seems to be related to increasing educational involvement of this group. For 16- and 17year-olds, school enrollments have risen to more than 95 percent, which presumably leaves relatively little room for additional increases. There might be more room for increased participation

\footnotetext{
${ }^{17}$ We also considered whether adding a similar term to the model, equal to the population share for the 16- to 24-year-old age bracket times a linear time trend, would change the results. This term did enter with a negative sign when added to the levels regression for $\log (L F C / L F C A D J L)$. However, the in-sample predictions were similar to the model without this term, and the out-of-sample forecast projections were virtually identical. Based on this evidence, we chose not to include this term in the model.
}

for 18- and 19-year-olds, for whom the enrollment percentage has risen to a little over 67 percent.

\section{WHY USE FEMALE LIFE EXPECTANCY DATA?}

The rising contribution from the life expectancy term is clearly the most important element of the model that produces a prediction for labor force growth that is higher than in other forecasts. However, we are not inclined to conclude that the model produces an overly optimistic projection for the labor force over the next decade. We are comfortable with the notion that increases in life expectancy raise the amount of wealth required to support a given flow of expenditures in retirement and thereby contribute to increases in the participation rates for older age brackets. Furthermore, other developments are likely to complement the impact of rising life expectancy and contribute to future increases in participation rates in older age brackets, including changes in parameters that influence Social Security retirement benefits, including the ongoing increase in the normal retirement age, the gradual weakening of the earnings test, and the expansion of the delayed retirement credit; rising educational attainment and the increasingly knowledge-based nature of employment; rising costs for health care; the expansion of defined-contribution retirement plans at the expense of defined-benefit plans; and the possibility that employers will adapt to a slowdown in the growth of the population of primeaged adults by increasing their recruitment and retention efforts for older, skilled workers.

These factors aside, why did we choose the particular form of the life expectancy term-the life expectancy of women at the age of 65, multiplied by the share of women 65 and older in the civilian noninstitutional population ("femaleweighted, female life expectancy”)? We considered other life expectancy terms, including the maleweighted, male life expectancy at age 65 , and the male-weighted, female life expectancy, among others, but we did not include them for several reasons. First, the female-weighted, female life expectancy worked well, with a positive coeffi- 
cient (as expected) and a high $t$-statistic of nearly 6 . Second, adding male-weighted life expectancies (for either men or women at age 65) did not materially improve fit and led to similar estimates of the contribution of changes in life expectancy to the growth of the labor force over the forecast period. Third, replacing the female-weighted, female life expectancy with either the maleweighted, male life expectancy or the maleweighted, female life expectancy caused the fit to deteriorate somewhat. Fourth, replacing the female-weighted, female life expectancy with the male- and female-weighted average life expectancy for men and women at age 65 caused the fit of the equation to deteriorate slightly. Fifth, we found support for a strong role for female life expectancy in a preliminary investigation into the labor force participation rates for specific age brackets of older men and women but not for male life expectancy.

Do these statistical results indicate a more important role for female life expectancy is reasonable? We think they do for several reasons. First, except when ill health intervenes, spouses tend to coordinate their work/retirement decisions, suggesting that the decisions of husbands will depend in part on the life expectancy of their wives, and vice versa. ${ }^{18}$ Second, on average, women live longer than men, suggesting that the life expectancy of wives is more important for savings and retirement decisions within the household. ${ }^{19}$ Third, Goda, Shoven, and Slavov (2007) demonstrate that many individuals experience a sharp increase in their net Social Security tax rate as they age; and, because of the parameters that determine taxes and benefits, on average men are likely to experience a sharper increase than women and at a much earlier age than women. For many men, the sharp increase occurs at or

\footnotetext{
${ }^{18}$ Munnell and Sass (2007) discuss many factors that influence the supply of labor for older Americans. They cite several papers showing a strong tendency for husbands and wives to retire within one to two years of each other.

19

On a related point, consider the work/retirement decisions of widows and widowers. They are likely to be influenced by their own life expectancy but not by the statistical life expectancy of the opposite gender. There are more widows than widowers, which accentuates the role of female life expectancy relative to male life expectancy.
}

before normal retirement age, creating a financial incentive toward earlier retirement that, on average, is larger for men than for women. This feature of Social Security tends to diminish the role of male life expectancy, and in the context of household decisionmaking, accentuates the importance of female life expectancy for the retirement decisions of both genders.

\section{CONCLUSION: IMPLICATIONS FOR POTENTIAL OUTPUT}

The estimate for trend growth of the labor force can be combined with other procedures described in a June 2008 presentation to generate a consistent estimate of potential GDP growth. ${ }^{20}$ Here we briefly sketch the implication for potential growth over the forecast through 2017. The main elements of potential GDP are (i) potential growth of hours worked in the nonfarm business sector, (ii) structural productivity growth in the nonfarm business sector, and (iii) trend growth in other GDP. The sum of the first two elements (apart from compounding) provides an estimate of potential GDP growth in the nonfarm business sector. That sector accounts for approximately three-fourths of total GDP.

Trend hours in the nonfarm business sector equals the trend in the workweek, which we assume is roughly flat in the forecast, times potential employment in that sector. The latter is equal to total potential civilian employment less employment in the "other" sectors outside the nonfarm business sector. Our procedures ensure that the "other" employments, which account for roughly 20 percent of total employment, are consistent with our forecasts for the "other" output, which includes government output, output of the household and institutional sectors, and agricultural output. Potential civilian employment is simply one minus the NAIRU (in decimal form) times the potential labor force. Using these methods, we estimate that potential hours growth through 2017 will be close to the estimate of potential labor

\footnotetext{
${ }^{20}$ See Matheny's presentation entitled "Research Update: Potential GDP” delivered at MA's June 10, 2008, Quarterly Outlook Meeting.
} 
force growth, or about 0.9 percent per annum. This reflects an assumption of a roughly flat trend in the workweek, an essentially constant value for the NAIRU, and an increase in "other" employment that averages about 1.1 percent.

Our estimate of structural productivity growth reflects contributions from capital deepening and growth of total factor productivity. We assume in the forecast that the latter will increase at a 1.2 percent annual rate. Based on projections regarding the growth of capital services in Macroeconomic Advisers' most recent long-term outlook as of this writing, capital deepening is expected to add another 0.8 percentage points to productivity growth in the forecast, resulting in structural productivity growth of about 2.0 percent and potential GDP growth in the nonfarm business sector of about 2.9 percent. Allowing for a contribution from "other" GDP of about 0.4 percentage points on average, this implies that total potential GDP growth would be expected to average about 2.6 percent through 2017. This is two-tenths higher than the Congressional Budget Office's (2008) projection that potential GDP growth will average 2.4 percent over the same period.

\section{REFERENCES}

Aaronson, Stephanie; Fallick, Bruce; Figura, Andrew; Pingle, Jonathan and Wascher, William. "The Recent Decline in the Labor Force Participation Rate and Its Implications for Potential Labor Supply." Brookings Papers on Economic Activity, Spring 2006, 1, pp. 69-134.

Bartik, Timothy J. "Displacement and Wage Effects of Welfare Reform," in David Card and Rebecca M. Blank, eds., Finding Jobs: Work and Welfare Reform. New York: Russell Sage Foundation, 2000, pp. 72-122.

Blank, Rebecca M. "What Did the 1990s Welfare Reform Accomplish?” Written for the Berkeley Symposium on Poverty and Demographics, the Distribution of Income, and Public Policy, December 2003; updated 2004; http://urbanpolicy.berkeley.edu/pdf/ Ch2Blank0404.pdf.
Congressional Budget Office. "The Budget and Economic Outlook: An Update.” CBO, September 2008; www.cbo.gov/ftpdocs/97xx/doc9706/09-08Update.pdf.

Goda, Gopi S.; Shoven, John B. and Slavov, Sita N. "Removing the Disincentives in Social Security for Long Careers.” NBER Working Paper No. 13110, National Bureau of Economic Research, May 2007; www.nber.org/papers/w13110.pdf?new_window=1.

Goodstein, Ryan. "The Effect of Wealth on the Labor Force Participation of Older Men.” Unpublished manuscript, University of North Carolina-Chapel Hill, March 2008; www.unc.edu/ rmgoodst/wealth.pdf.

Macroeconomic Advisers. Long-Term Economic Outlook. September 24, 2008.

Munnell, Alicia H. and Sass, Steven A. "The Labor Supply of Older Americans." Working Paper No. 2007-12, Center for Retirement Research at Boston College, June 2007; http://crr.bc.edu/images/stories/ Working_Papers/wp_2007-12.pdf?phpMyAdmin= 43ac483c4de9t51d9eb41.

Matheny, Ken. "Research Update: Potential GDP," presented at Macroeconomics Advisers' Quarterly Outlook Meeting, June 10, 2008, St. Louis, Missouri.

Social Security Administration. Personal Responsibility and Work Opportunity Reconciliation Act of 1996 (Public Law 104-193; §115.42 U.S.C. 862a), August 22, 1996; www.ssa.gov/OP_Home/comp2/F104-193.html.

U.S. Census Bureau. Current Population Survey. www.census.gov/cps/. 
